\title{
COMBINED ADAPTIVE CONTROL AND SVC FOR A TURBOGENERATOR
}

\author{
N. A. Nagem R. A. Amer S. M. Osheba \\ Department of Electrical Engineering, Faculty of Engineering, Menoufiya \\ University, Egypt.
}

\begin{abstract}
This paper presents an advanced control approach for a synchronous generating unit based on the combination of an adaptive controller and a static var compensator (SVC). The considered electrical power system consists of a turbogenerator connected to an infinite bus via a step-up transformer and a double circuit transmission line. Firstly, a fairly detailed model of the system is built to simulate system performance at various operating points using MATLAB-SIMULINK environment. A performance criterion has been considered and a recursive least square (RLS) algorithm is utilized to determine the parameters of the proposed adaptive controller. This control algorithm is preferred for its simplicity and it is more suitable for online applications. SVC is inserted at the generator terminal for power oscillation damping and stability improvement with fast acting voltage regulation. The system performance with and without the control strategy is evaluated and the results are presented in a comparative form with conventional control systems. The results obtained over a wide range of operating points show that a significant improvement of performance can be achieved via a combination of adaptive and SVC controllers with enhanced damping and voltage recovery. The results presented in the paper are of prime importance to engineers in power systems utilities, forming a guide to improve performance.
\end{abstract}

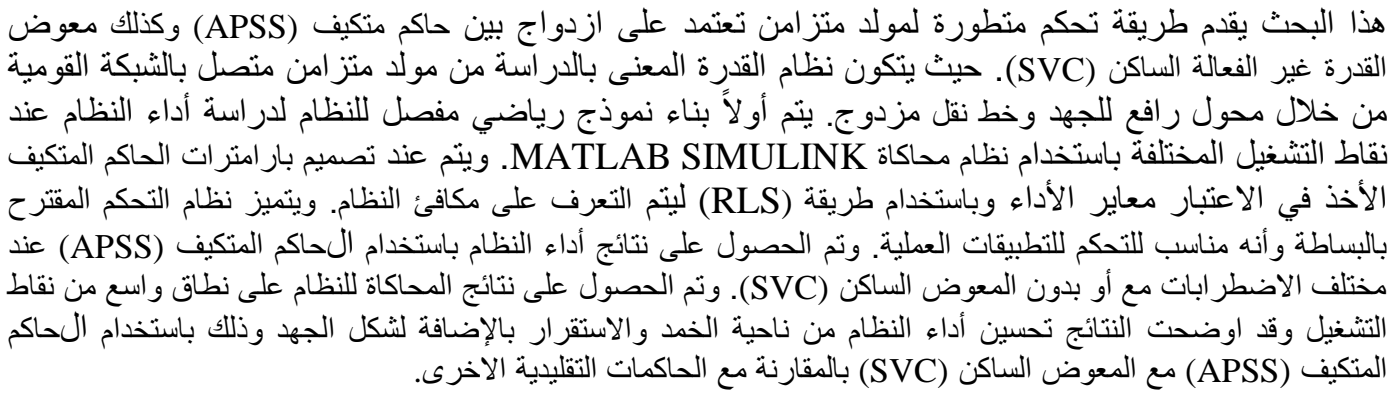

Key-words: SVC, APSS, FACTS, CPSS, RLS

\section{Introduction}

Control strategies for electric power interconnections play a prominent role in reliable and stable operation of power systems. Growth in the interconnections such as the interconnections between the operating plants and distribution stations or substations create a growing need for flexibility, reliability, fast response and accuracy in the fields of electric power generation, transmission, distribution and consumption [1]. To improve the power system performance and to extend its operational margin of stability during the steady-state and transient conditions, power systems are equipped with different types of control systems [2]. Excitation control using automatic voltage regulator (AVR) and Provides the electrical damping torque in phase with the speed deviation to improve power system damping. The common type is the speed governor (SG) systems represent the basic conventional control strategies [3]. While the conventional speed governor systems (SG) is required for keeping the droop characteristics, the AVR with a high gain is required to maintain the terminal voltage within a recommended tolerance $( \pm 0.5 \%)$ [UK standard] [2]. unfortunately, both speed governor and high gain AVR add negative damping to the systems, leading to a detoriation in performance [4]. Subsequently, conventional power system stabilizers (CPSS) are added to substitute for the adverse effects of SG and AVR systems [5].

The basic function of conventional control system is to add positive damping to the rotor oscillations using an auxiliary stabilizing signal. It conventional power system stabilizer (CPSS) which introduced to improve system performance and stability during normal and abnormal conditions [6].

Engineering Research Journal, Vol. 37, No. 4, October 2014, pp: 397-405. 
However, CPSS has fixed-parameter designed for a specific operating point, which generally cannot maintain the same improvement of performance at other operating points. Moreover, it requires a linearized model for the controlled system [7].

The configurations and techniques of the power systems are changed over the time, while the CPSS parameters are optimum for only one of these operating points [8]. A more sophisticated controller which can maintain good damping over a wide range of operating conditions is therefore needed. This can be achieved by tuning the parameters of the controller on-line based on real time measurements [9].

Adaptive PSS (APSS) offers a good alternative. The function of APSS is to adapt its parameters while the system moves from one operating point to another. Therefore, the adaptive controller has a potential to improve power system performance and stability [10]

This paper presents an approach for improving system performance over a wide range of operating conditions based on combining the advantages of adaptive control and FACTS capability.

The adaptive stabilizer proposed in this study is based on the minimization of a suggested performance index. The recursive least square squares identification algorithm is utilized to estimate the model parameters every sampling interval. Flexible ac transmission systems (FACTS) are playing an increasingly important role in electrical power systems. FACTS devices have been widely in operation. Ratings range from 60 to 600 MVAR [11]. The basic function of FACTS devices is to enhance the power system stability, performance and to improve power system damping. FACTS devices can be classified based on the way they are connected to the power system, into Series, Shunt, and Combination of Series-shunt devices [12].

SVC can be considered as a "first generation" FACTS devices and uses thyristor controllers consisting of a combination of fixed capacitor in conjunction with thyristor-controlled reactor[13][14]. SVC is a shunt-connected static var generator or absorber whose output is adjusted to exchange capacitive or inductive current so as to maintain or control specific parameters of the electrical power system (typically bus voltage). The combination of both techniques is described subsequently.

\section{System modeling}

The system consists of a synchronous generator connected to an infinite bus through a stepup transformer and a double circuit transmission line. The generator is driven by a steam turbine with fast valving system and is excited using a fast acting thyristor exciter. A schematic diagram of the power system considered in this study is shown in Fig.1. A description of the individual elements of the system is given subsequently and the parameters are shown in the Appendix.

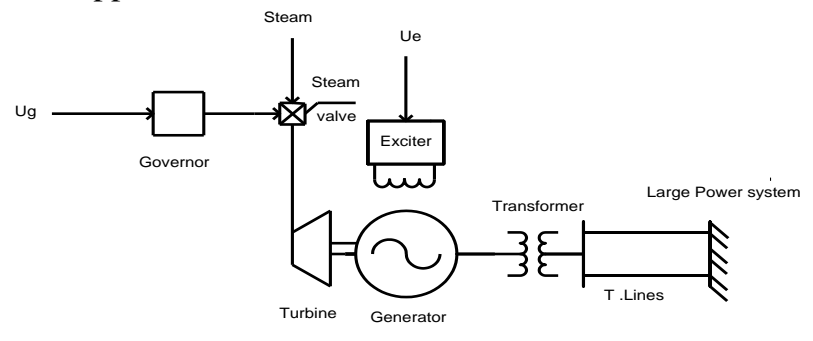

Fig.1 Schematic diagram of a turbo generator system 2.1. Generator

Based on park's model used $\mathrm{d}-\mathrm{q}$ axes transformation, a Full-detailed seventh-order nonlinear mathematical model representation is established to represent this power system. The differential equations are arranged as a set of first order equations as following [15]:

$\dot{\delta}=\omega$

$\dot{\omega}=\frac{\omega_{0}}{2 \mathrm{H}}\left(\mathrm{T}_{\mathrm{m}}-\mathrm{T}_{\mathrm{e}}\right)$

$\mathrm{T}_{\mathrm{e}}=\psi_{\mathrm{d}} \mathrm{i}_{\mathrm{q}}-\psi_{\mathrm{q}} \mathrm{i}_{\mathrm{d}}$

$\dot{\psi}_{\mathrm{f}}=\omega_{\mathrm{o}}\left(\mathrm{E}_{\mathrm{fd}} \frac{\mathrm{R}_{\mathrm{f}}}{\mathrm{X}_{\mathrm{fd}}}-\mathrm{i}_{\mathrm{f}} \mathrm{R}_{\mathrm{F}}\right)$

$\dot{\psi}_{\mathrm{d}}=\omega_{\mathrm{o}}\left(\mathrm{v}_{\mathrm{d}}+\mathrm{i}_{\mathrm{d}} \mathrm{R}_{\mathrm{a}}+\psi_{\mathrm{q}}\right)+\omega \psi_{\mathrm{q}}$

$\dot{\psi}_{\mathrm{q}}=\omega_{\mathrm{o}}\left(\mathrm{v}_{\mathrm{q}}+\mathrm{i}_{\mathrm{q}} \mathrm{R}_{\mathrm{a}}-\psi_{\mathrm{d}}\right)-\omega \psi_{\mathrm{q}}$

$\dot{\psi}_{D}=-\omega_{0} \mathrm{i}_{\mathrm{D}} \mathrm{R}_{\mathrm{D}}$

$\dot{\psi}_{Q}=-\omega_{\mathrm{o}} \mathrm{i}_{\mathrm{Q}} \mathrm{R}_{\mathrm{Q}}$

The transmission system is considered as short line. So, it could be approximated by a series lumped resistance and reactance. The $\mathrm{d}-\mathrm{q}$ machine terminal voltage equations related to the infinite bus are:

$\mathrm{V}_{\mathrm{d}}=\mathrm{V}_{\mathrm{b}} \sin \delta+\mathrm{i}_{\mathrm{d}} \mathrm{R}_{\mathrm{e}}-\mathrm{i}_{\mathrm{q}} \mathrm{X}_{\mathrm{e}}$

$\mathrm{V}_{\mathrm{q}}=\mathrm{V}_{\mathrm{b}} \cos \delta+\mathrm{i}_{\mathrm{q}} \mathrm{R}_{\mathrm{e}}+\mathrm{i}_{\mathrm{d}} \mathrm{X}_{\mathrm{e}}$

Where $\mathrm{R}_{\mathrm{e}}=\mathrm{R}_{\mathrm{T}}+\mathrm{R}_{\mathrm{L}}$.

The turbine and governor system is shown in Fig. 2. It represents a simple steam turbine model with a single gain, $K_{t}$, and time-constant; $T_{t}[16]$. The speed governor is also considered with single gain $\mathrm{K}_{\mathrm{g}}$ and single time-constant $\mathrm{T}_{\mathrm{g}}$.

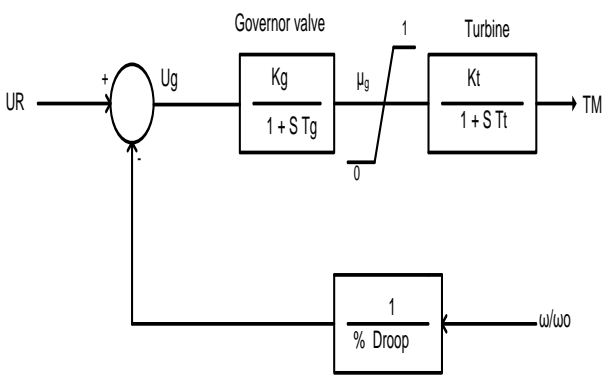

Fig. 2 Representation of turbine and governor system

\subsection{Excitation System}

Various types of exciters have been used with large generators the used exciters are rotary and static 
exciters. The static exciter is a thyristor exciter, which provides very fast response $[17,18]$. In this study, the steam generating unit is equipped with a fast acting thyristor exciter. An automatic voltage regulator (AVR) with high gain is used to maintain the terminal voltage deviation within a tolerance value of 0.05 p.u. as load condition varies. The block diagram of the excitation system is shown in Fig .3. Under heavy load conditions the continuously acting voltage regulators may produce a negative damping. To eliminate this effect and to improve the system damping, an artificial means of producing torques in phase with the speed are introduced. The network used to add a stabilizing signal is called power system stabilizer (PSS). The PSS is a lead-lag network with two time constants $T_{1}$ and $T_{2}$ and gain $\mathrm{G}_{\mathrm{s}}$. The transfer function of the PSS is shown in Fig .3

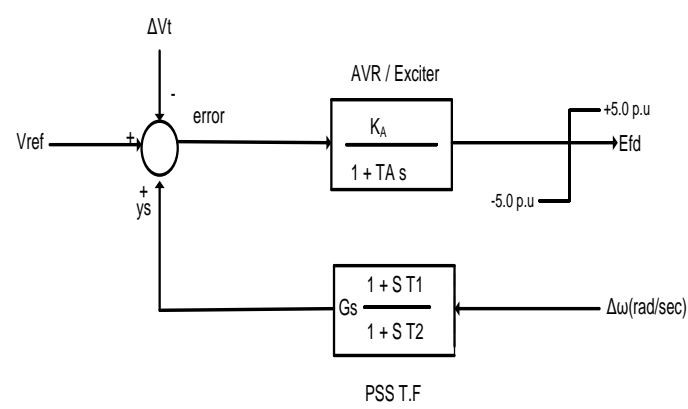

Fig .3 block diagram for the Excitation system

\subsection{Simulation results of conventional controllers}

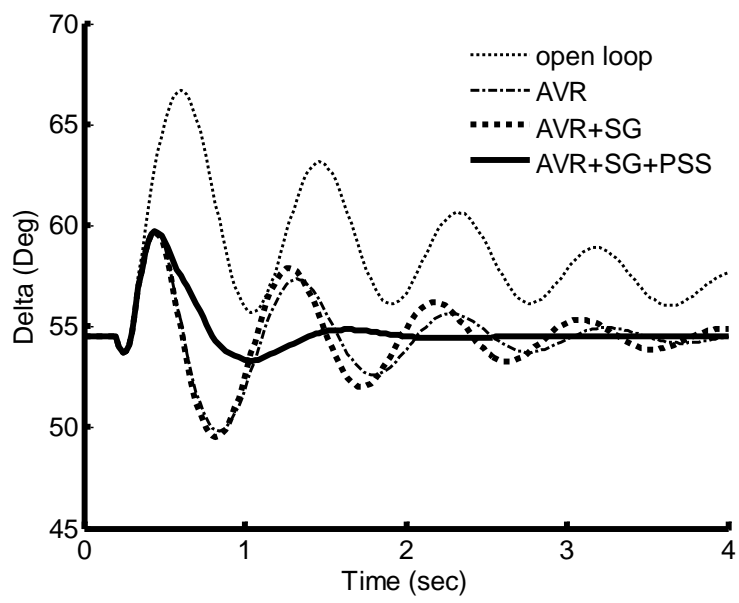

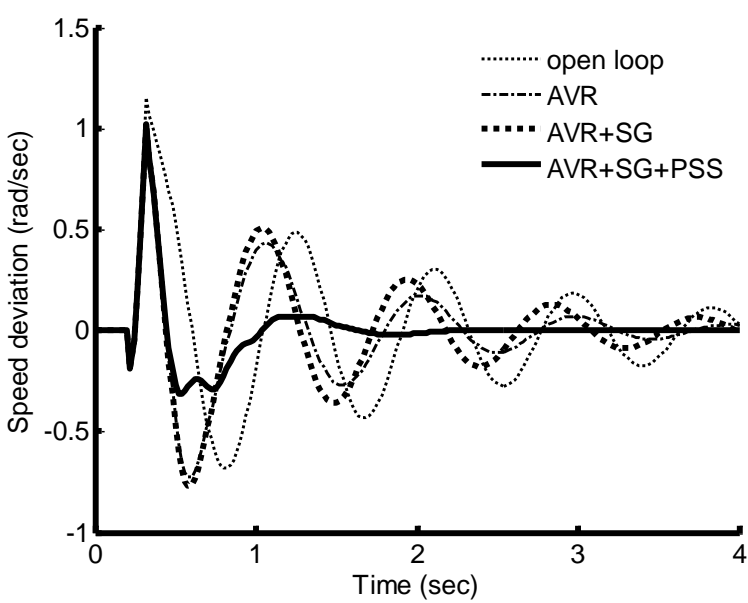

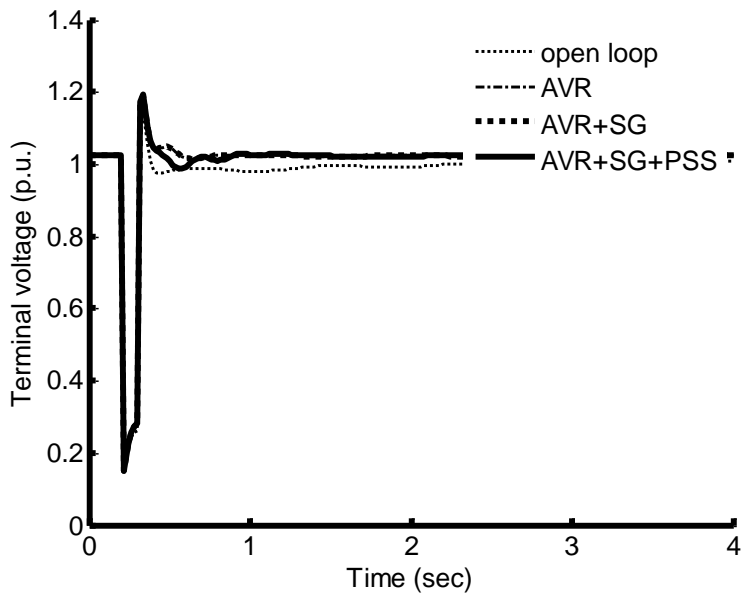

Fig. 4 system response to 3-phase short circuit for $120 \mathrm{~ms}$ at lagging p.f.

\section{Adaptive stabilization}

\subsection{Modeling of system output}

Considering that the system output is sampled at discrete intervals of time leading to the following output equation:

$\mathrm{y}(\mathrm{k})=\sum_{i=1}^{n}\left[\mathrm{a}_{\mathrm{i}} \mathrm{y}(\mathrm{k}-\mathrm{i})+\mathrm{b}_{\mathrm{i}} \mathrm{u}(\mathrm{k}-\mathrm{i})\right]$

Where $y(k)$ and $u(k)$ are the sampled system output and input at time $k T_{s}$ respectively. $T_{s}$ is the sampling period, $k$ is an integer, $\mathrm{n}$ is the model order, $\mathrm{a}_{\mathrm{i}}$ and $\mathrm{b}_{\mathrm{i}}$ are the model parameters to be estimated every sampling period

\subsection{Performance index}

$\mathrm{I}(\mathrm{k})=[y(k+1)]^{2}+q^{\prime}\left[\frac{d y(k+1)}{d t}\right]^{2}+\mathrm{r}[u(k)]^{2}$

By taking into consideration the system output and its first derivative as well as the control effort. Thus, the performance index, $I(k)$ defined for the conventional synchronous generator was of the form in $\mathrm{Eq}(12)$

[19].

Where $\left(q^{\prime}, r\right)$ are positive weighting constants to be properly pre-specified. 
"

\subsection{Control law}

To simplify the minimization task, the first and second derivative terms in Eq (12) and $\mathrm{Eq}$ (19) are replaced by their following approximations: $d y(k+1) / d t=[y(k+1)-y(k)] / T$

$\mathrm{d}^{2} \mathrm{y}(\mathrm{k}+1) / \mathrm{dt}^{2}=[\mathrm{y}(\mathrm{k}+1)-2 \mathrm{y}(\mathrm{k})+\mathrm{y}(\mathrm{k}+1)] / \mathrm{T}^{2}$ (14)

The performance index then takes the form: $\mathrm{I}(\mathrm{K})=[y(k+1)]^{2}+\mathrm{q}_{1}[y(k+1)-y(k)]^{2}+\mathrm{r}[u(k)]^{2}$ (15)

Where $q_{1}=q^{\prime} / T_{s}^{2}$. Substituting $y(k+1)$ from Eq (11) into Eq (15), and setting $\partial I(k) / \partial u(k)$ to zero yields, after some mathematical manipulation, the following optimal control signal:

$\mathrm{u}(\mathrm{k})=\left[b_{1} q_{1} y(k)-s_{1}(k)\right] /\left[r+b_{12}\left(1+q_{1}\right)\right](16)$

Where:

$s_{1}(\mathrm{k})=b_{1}\left(1+q_{1}\right) \cdot\left[\sum_{i=1}^{n} a_{i} \mathrm{y}(\mathrm{k}+1-\mathrm{i})+\sum_{i=2}^{n} b_{i} \mathrm{u}(\mathrm{k}+\right.$ $1-\mathrm{i})$

By taking into consideration the system output and its second derivative (acceleration) as well as the control effort. The following performance index is suggested. [20].

$\mathrm{I}(\mathrm{k})=[y(k+1)]^{2}+q^{\prime \prime}\left[\frac{d^{2} y(k+1)}{d t^{2}}\right]^{2}+\mathrm{r}[u(k)]^{2}$

Where $\left(q^{\prime \prime}, r\right)$ are positive weighting constants to be properly pre-specified. Substitute from Eq (14) into Eq (18) and from Eq (11) into Eq (18). Then the performance index takes the form:

$\mathrm{I}(\mathrm{K})=[y(k+1)]^{2}+\mathrm{q}_{2}[y(k+1)-2 y(k)+y(k-$ 1) $]^{2}+\mathrm{r}[u(k)]^{2}$

Where $\mathrm{q}_{2}=\mathrm{q}^{\prime \prime} / \mathrm{T}_{\mathrm{s}}^{4}$, setting $\partial I(k) / \partial u(k)$ to zero yields, after some mathematical manipulation, the

following optimal control signal:
$\mathrm{u}(\mathrm{k})=\left[b_{1} q_{2}(2 y(k)-y(k-1))-s_{2}(k)\right] /\left[r+b_{12}\left(1+q_{2}\right)\right](k)=\frac{\mathrm{P}(\mathrm{k}-1) \phi(\mathrm{K})}{\lambda+\phi^{\mathrm{T}}(\mathrm{k}) \mathrm{P}(\mathrm{k}-1) \phi(\mathrm{k})}$

Where:

$$
s_{2}(k)=b_{1}\left(1+q_{2}\right)\left[\sum_{i=1}^{n} a_{i} \mathrm{y}(\mathrm{k}+1-\mathrm{i})+\right.
$$$$
\left.\sum_{i=2}^{n} b_{i} \mathrm{u}(\mathrm{k}+1-\mathrm{i})\right]
$$

\subsection{Recursive Least Squares Identifier}

Several methods of identification can be used to obtain an estimate for the model parameters for example [21]:

-Recursive Least Squares (RLS) identification

-Recursive Extended Least Squares (RELS) identification

-Recursive Maximum Likelihood (RML) Method

-The Bayesian Estimation

-The Square Root Filtering

-Kalman Filter as Parameter Estimator

Among different identification algorithms for on-line identification, Recursive Least Squares (RLS) methods have the advantages of simple calculation and good convergence properties. Most adaptive systems are based on recursive identification. As shown in Fig. 5

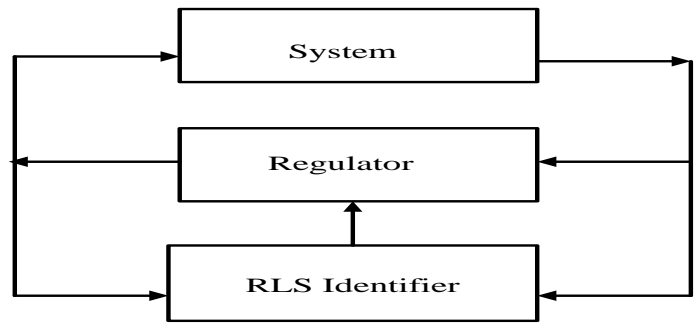

Fig.5 a general scheme for RLS

The objective of the identification process in the proposed stabilizer is to specify values for the unknown parameters $\left(a_{i}, b_{i}\right)$ so that the discrete-time model (identifier model) given by Eq (11) represents the synchronous generator system dynamics satisfactorily around a quiescent operating point. A modified version of the RLS identification algorithm is used to estimate the model parameters at every sampling interval based on the system input and output data [22]. The principle of the least squares method is the choose of the model parameters $\left(a_{i}, b_{i}\right)$ so that the sum of the error squares between the actually observed value (system output) and the computed value (model output) is minimized [23]. . By defining a vector of the model parameters $\theta(\mathrm{k})$ as:

$\theta(k)=\left[a_{1}, a_{2}, \ldots \ldots, a_{n} \quad, b_{1}, b_{2} ; \quad, b_{n}\right]^{\mathrm{T}}$

And a vector of the system input-output data $\phi(\mathrm{k})$ as: $\Phi(\mathrm{k})=[y(k-1), y(k-2), y(k-n), u(k-$
1), $u(k-2), u(k-n)]^{T}$

The RLS identification algorithm for the parameters estimation can be summarized as follows [24].

$\mathrm{e}(\mathrm{k})=\mathrm{y}(\mathrm{k})-\phi^{\mathrm{T}}(\mathrm{k}) \theta(\mathrm{k}-1)$

$q_{2}(k)=\frac{\mathrm{P}(\mathrm{k}-1) \phi(\mathrm{K})}{\lambda+\phi^{\mathrm{T}}(\mathrm{k}) \mathrm{P}(\mathrm{k}-1) \phi(\mathrm{k})}$

$P(k)=\frac{\left[\mathrm{I}-\mathrm{K}(\mathrm{K}) \phi^{\mathrm{T}}(\mathrm{k})\right] \mathrm{P}(\mathrm{k}-1)}{\lambda}$

$\theta(\mathrm{k})=\theta(\mathrm{k}-1)+\mathrm{K}(\mathrm{k}) . \mathrm{e}(\mathrm{k})$

Where $P$ is the covariance matrix, $K$ is the gain vector and $\lambda$ is the forgetting factor which lies between 0 and 1 . The criterion of the RLS identification is to determine the most likely value, $\theta(\mathrm{k})$.

\subsection{Simulation Results}

Fig. 6 and Fig. 7 show the system response to a 3phase short circuit for $120 \mathrm{~ms}$. The system response with PSS is compared with adaptive controllers. Fig. 6 shows the response when past adaptive $n=3$ is used while, Fig. 7 shows the response with utilizing the proposed adaptive $n=3$. From this results the APSS is better than conventional PSS (lower first swing, lower steady state error and more stable), but also shows that the performance of proposed APSS is better than that of past APSS with the same model order. The Figures show also the parameters variation with time, the parameters started with 
constant values then after short circuit occurrence they oscillate and reach to their final values.
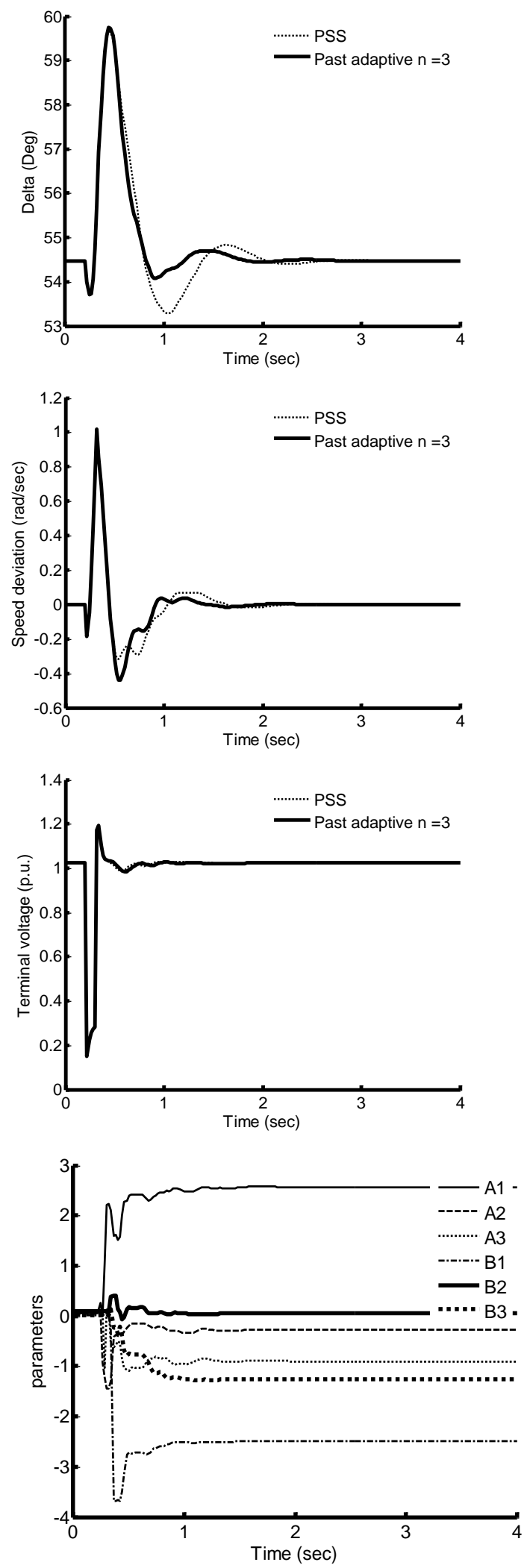

Fig 6 system response to 3-phase short circuit for $120 \mathrm{~ms}$ at lagging p.f.
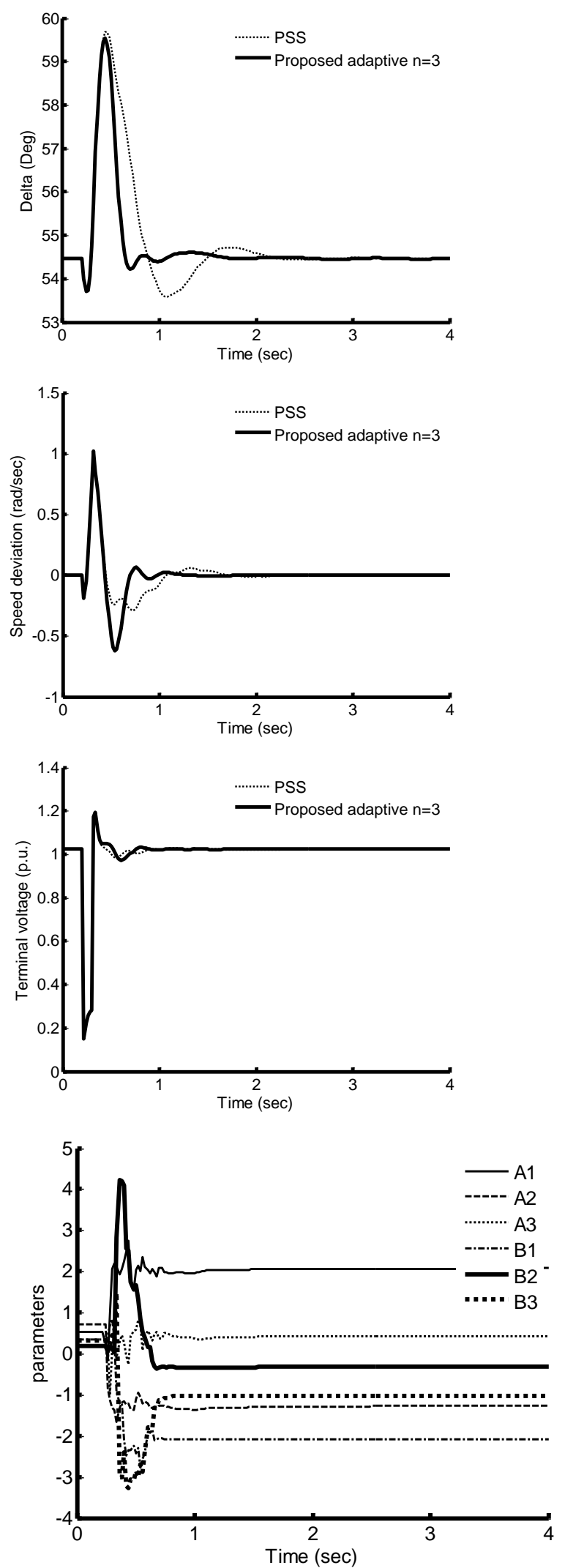

Fig 7 system response to 3-phase short circuit for $120 \mathrm{~ms}$ at lagging p.f. 


\section{Addition of Static VAR Compensator 5.1 SVC Structure}

In its simplest form, the SVC consists of a Thyristor Controlled Reactor (TCR) in parallel with a bank of capacitors. From an operational point of view, the SVC behaves like a shunt-connected variable reactance, which either generates or absorbs reactive power in order to regulate the voltage magnitude at the point of connection to the AC network [25, 26, 27].It is used extensively to provide fast reactive power and voltage regulation support. The firing angle control of the thyristor enables the SVC to have almost instantaneous speed of response. A schematic representation of the SVC is shown in Fig. 8 where a three-phase, three winding transformer is used to interface the SVC to a high-voltage bus. The transformer has two identical secondary windings: one is used for the delta-connected, sixpulse TCR and the other for the star-connected, three-phase bank of capacitors, with its star point floating. The three transformer windings are also taken to be star-connected, with their star points floating. The SVC can be considered as a variable susceptance.

The block diagram shown in Fig. 9 represents the SVC with lead-lag controller. A conventional lead-lag controller is installed in the feedback loop to generate SVC stabilizing signal. The susceptance of the SVC $\left(B_{\mathrm{SVC}}\right)$ is governed by the following equation [28]:

$\frac{d B_{s v c}}{d t}=\frac{1}{T_{F}}\left[K_{F}\left(B_{r e f}+U_{s v c}\right)-B_{s v c}\right]$

Where: $K_{F}, T_{F}$ are the gain and time constant of the SVC, respectively and $B_{\text {ref }}$ is the reference susceptance of the SVC. Usually $K_{F}$ and $T_{F}$ are kept constant at 1.0 and $0.05 \mathrm{sec}$, respectively. Fig 10 shows Matlab-Simulink model of SVC.

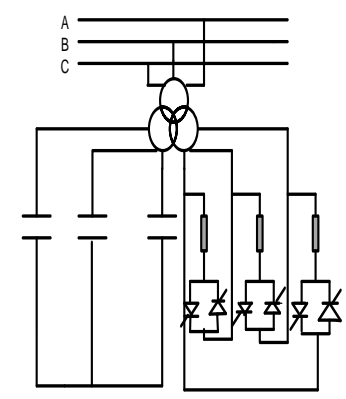

(a) Three-phase representation

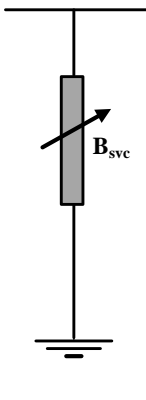

(b) Equivalent circuit
Fig. 8 Representation of SVC comprising fixed capacitors (FC) and thyristor controlled reactors (TCR)

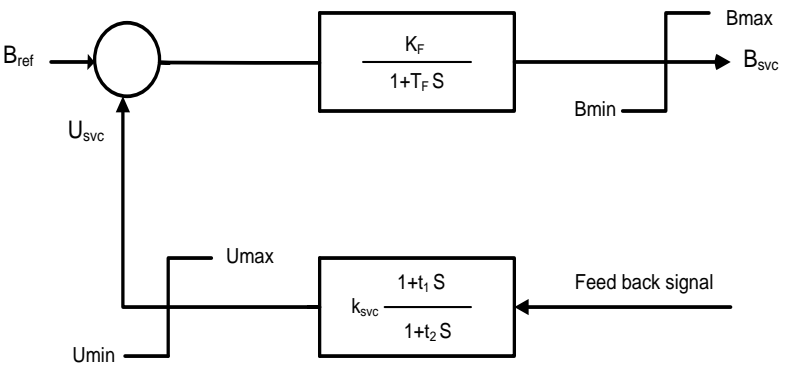

Fig. 9 SVC with lead-lag controller

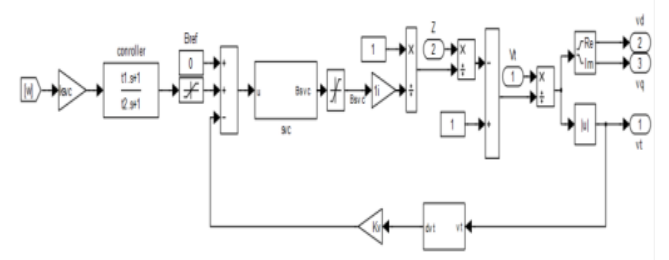

Fig. 10 MATLAB-SIMULINK model of SVC

\subsection{Simulation Results}

To achieve a higher level of accuracy in the predicted results and draw a general conclusion from the results, detailed representation were made for all system components. The transient performance of the simulated non-linear system with the conventional excitation control (AVR and PSS) and when the new controller (APSS) to the system added were examined for symmetrical three-phase short circuit (120 ms duration) at the transformer high voltage side. Initially, the simulation results are obtained in comparative form using (CPSS Vis APSS) as shown in Figs.(6) and (7) taking the effect of AVR with both APSS and CPSS. These results illustrate that the best performance of the system obtained with the APSS as it provide good damping to electromechanical mode of oscillations and all system variables quickly return to their initial values. Then the simulation results are obtained in comparative form using (APSS Vis adding SVC) as shown in Figs. (11) and (12) the results show that by adding SVC to the adaptive controller the stability is increased in form of the first swing is less and the steady state error is also decreases. 

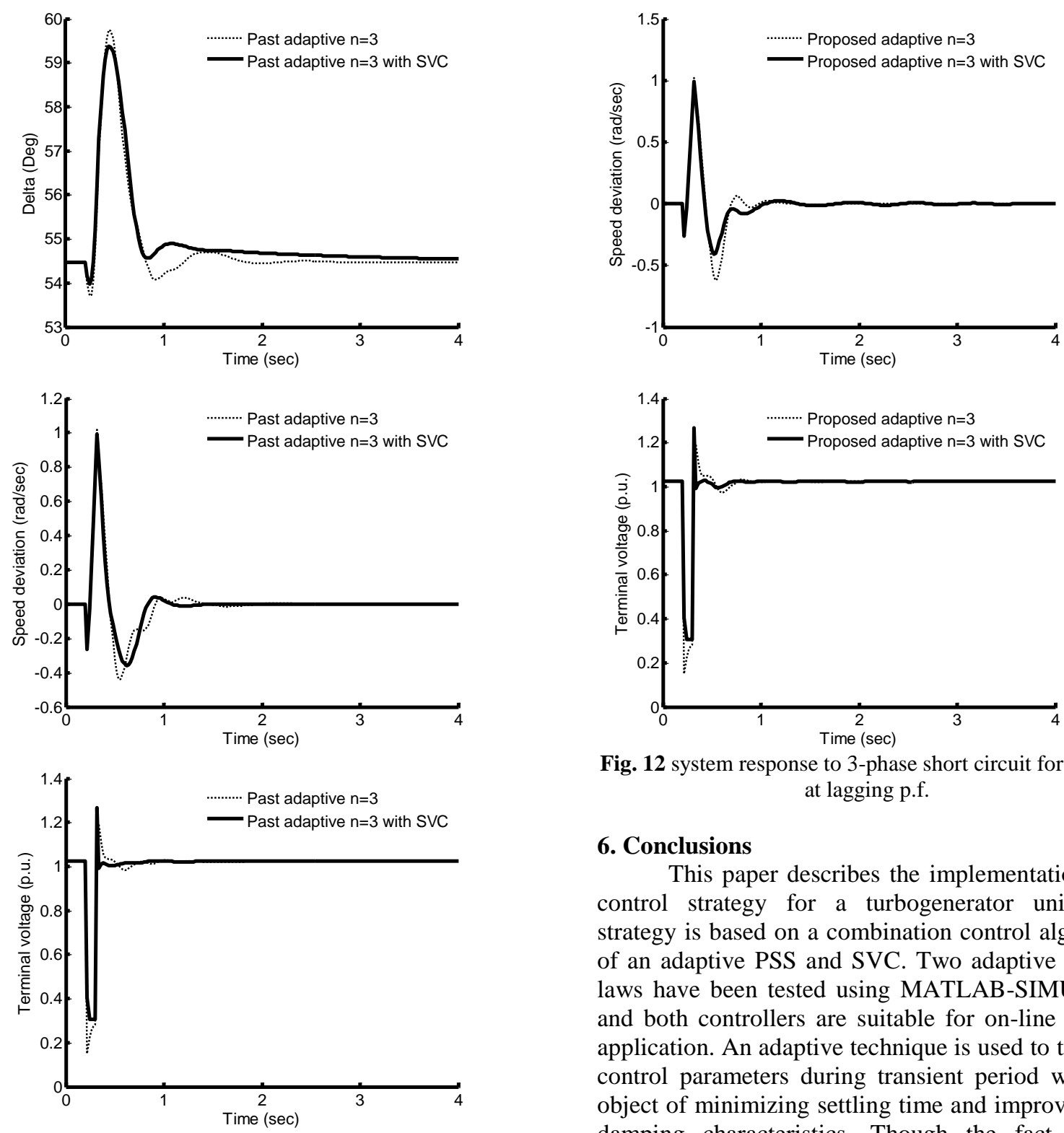

Fig. 12 system response to 3-phase short circuit for $120 \mathrm{~ms}$ at lagging p.f.

\section{Conclusions}

This paper describes the implementation of a control strategy for a turbogenerator unit. The strategy is based on a combination control algorithm of an adaptive PSS and SVC. Two adaptive control laws have been tested using MATLAB-SIMULINK and both controllers are suitable for on-line control application. An adaptive technique is used to tune the control parameters during transient period with the object of minimizing settling time and improving the damping characteristics. Though the fact that a stabilizing signals drived from shaft acceleration provides better performance, the two control laws give similar results. This shows that the parameter tuning is very efficient and fast in determining the optimal parameters. The results also show that the addition of SVC extends the stability margin. The results presented in the paper show a novel trend to guide power system engineers for optimal utilization of generating power stations.

\section{List of Symbols}

$p$ The derivative operator ' $\mathrm{d} / \mathrm{dt}$ '

$\omega_{0}$ Angular frequency of the infinite bus

$\omega$ Angular speed deviation of the rotor

$\Psi_{d}, \Psi_{q}$ Stator flux linkages in d- and q-axis circuits

$V_{d}, V_{q}$ Stator terminal voltage in d-and q-axis circuits $\mathrm{i}_{\mathrm{d}}, \mathrm{i}_{\mathrm{q}}$ Stator currents in $\mathrm{d}$ - and $\mathrm{q}$ - axis circuits 
$\mathrm{R}_{\mathrm{a}}$ Stator resistance

$\mathrm{R}_{\mathrm{f}}, \mathrm{i}_{\mathrm{f}}$ Field circuit resistance and current

$X_{e}, r_{e}$ Combined reactance and resistance of transformer and transmission lines

$\delta$ Rotor angle

$\mathrm{T}_{\mathrm{m}}$ Input mechanical torque

$\mathrm{T}_{\mathrm{e}}$ Output electrical torque

$K_{F}, T_{F}$ are the gain and time constant of the SVC, respectively

$\mathrm{B}_{\text {ref }}$ is the reference susceptance of the SVC

$P$ is the covariance matrix

$K$ is the gain vector

$\lambda$ is the forgetting factor

$y(k)$ and $u(k)$ are the sampled system output and input

$T_{s}$ is the sampling period

$k$ is an integer

$n$ is the model order

$\mathrm{a}_{\mathrm{i}}$ and $\mathrm{b}_{\mathrm{i}}$ are the model parameters

Appendix:

1) Machine parameters (p.u)

$\mathrm{X}_{a d}=1.86 \quad \mathrm{X}_{q}=1.91$

$\mathrm{X}_{a q}=1.77 \quad \mathrm{X}_{K Q}=1.96$

$\mathrm{X}_{f d}=1.97 \quad \mathrm{X}_{K D}=1.94$

$\mathrm{R}_{K Q}=0.0084 \quad \mathrm{R}_{K D}=0.0078$

$\mathrm{r}_{a}=0.005 \quad \mathrm{~T}_{\mathrm{e}}=0.5$

$\mathrm{r}_{f}=0.0015 \quad \mathrm{R}=0.04$ p.u. HZ/MW

2) Transmission system:

$X_{T}=0.1$ p.u. $\quad R_{T}=0.038$ p.u.

$X_{L}=0.35$ p.u. $\quad R_{L}=0.025$ p.u.

\section{References}

[1] Pardeep Singh.Virk al. Int. journal of Engineering Research and application "Power System Stability Improvement of Long Transmission Line System by using Static Var Compensator(SVC)", vol.3, Issues, Sep-Oct 2013, pp.01-03.

[2] G. A. Morsy, "Control of Multi-machine power systems”, Ph.D. Thesis, Menoufia University, 1991.

[3] Ge BaoJun, Xin Peng, Lv Yanling, "The Excitation System Simulation of Huge Hydrogenerator," Power and Energy Engineering Conference (APPEEC), pp. 1-4, March 28-23, 2010.

[4] Valentine, C. "Generator Voltage Regulators and Their Applications", Third Edition, 1948, Westinghouse Co. Ltd, American.

[5] Xue Wu, Li Wenyun, Cao Kunnan, Zhao Yun, "Improvement of dynamic stability of Yunnan Province and South-China power system by power system stabilizer (PSS)," International Conference on Power System Technology, Vol. 3, pp. 1179-1183, 2000.

[6] K. R. Padiyar, "Power System Dynamics: Stability and Control", John Wiley \& Sons (Asia) Pre Ltd., 1996, E. A. Mohamed et al, "Efficient Power System Stabilizer Configuration Based on Linear
Optimal Control and ANN". MEPCON 2000, Ain Shams University, Egypt, March 28-30, 2000.].

[7] D.A. Pierre, "A Perspective on Adaptive Control of Power Systems", IEEE Trans. on Power Systems, vol. PWRS-2, no. 5, Sep. 1987, pp. 387-396.

[8] G. Shabib, "Applications of discrete pole placement on power system oscillation damping control using $\delta$ models", Mediterranean Conference on Control and Automation, 2011, 0.1109/MED.2011.5982984, 51099149.

[9] A.H. M. A. Rahim, E. P. Nowicki, O. P. Malik "Enhancement of power system dynamic performance through an on line self tuning adaptive SVC controller", Electric Power Systems Research, Vol. 76, Issues 9-10, 2006, pp 801-807.

[10] Payman Shamsollah, CALGARY, ALBERTA JULY, 1997, "Neural Adaptive Power System Stabilizer".

[11] K. R. Padiyar, A. M. Kulkarni, Sãdhanã 22(6), 781 (1997).

[12] N. G. Hingorani and L. Gyugyi, "Understanding FACTS: Concepts \&Technology of Flexible AC Transmission Systems", John Wiley\&Sons, November 1999

[13] L. Gyugyi, IEEE Transactions on Industry Applications 15(5), 521 (1979).

[14] T. J. E. Miller, Reactive Power Control in Electric Systems, Wiley, New York, 1982.

[15] S.M.osheba et al,"Comparison of transient performance of superconducting and conventional generators in a multimachine system", IEEE-pro.135, pt. C, No.5, Sep.1988, and pp.389-395[16] IEEE Committee Report, "Dynamic models for steam and hydro turbines in power system studies, "IEEE Trans., PAS-92, PP.1904-1915, 1973.

[17] A.H. El-abiad,"Power systems analysis and planning",purdue University, West Lafayette,Indiana USA, 1983

[18] H.A.Khattab, "Stabilization of a superconducting Generating Unit in a Multi-machine System",Ph.D. Thesis, Menoufia University, Faculty of Eng. 2007.

[19] C.M. Lim, "A self-tuning stabilizer for excitation or governor control of power systems", IEEE PES summer meeting, Portland, Oregon, July 1988, Paper 88 SM 738-7.

[20] C.M. Lim and T. Hiyama, "Self tuning control scheme for stability enhancement of multimachine power systems", IEE Proc., Pt. C, V.137, N.4, pp.269-275, 1990.

[21] L. Ljung and T.Soderstrom, "Theory and Practice of Recursive Identification", The MIT Press Cambridge, Massachusetts London, England, 1983.

[22] P.P. Kanjilal, "Adaptive prediction and predictive control”, Peter Peregrinus Ltd., UK, 1995. [23] C.J. Harris, and S.A. Billings, "Self-tuning and adaptive control: theory and applications", Peter Peregrinus Ltd., UK, 1981 
[24] N.K. Sinha and B. Kuszta, "Modelling and identification of dynamic systems", Book, USA, 1983.

[25] M. M. Farasangi, H. Nezamabadi-pour, Y. H. Song, and K. Y. Lee, "Placement of SVCs and Selection of Stabilizing Signals in Power Systems", IEEE Transaction on power systems, Vol. 22, No. 3, pp. 1061-1071, August 2007.

[26] K. Ramar, A. Srinivas, "Design of SVC Stabilizers for Multi-Machine Power System", IEEE International Conference on Advances in Power
System Control, Operation and Management, pp. 112-118, Hong Kong, November 1991.

[27] M. H. Haque, "Best Location of SVC to Improve First Swing Stability Limit of a Power System", Electric Power Systems Research, Vol. 77pp. 1402-1409, 2007.

[28] M. A. Abido, Y. L. Abdel-Magid, "Coordinated design of a PSS and an SVC based Controller to Enhance Power System Stability", Electrical Power and Energy Systems, Vol. 25, pp. 695-704, 2003. 